\title{
Pertencer ao passado
}

\section{Miguel Sanches Neto}

Doutor emTeoria Literánia pela Unicamp, professor-associado da Universidade Estadual de Ponta Grossa, onde leciona Literatura Brasileira. É autor, entre outros, dos romences Chove sobre minha infância, Umamor anarquista, A primeira mullher e Chá das cinco como vampiro.

Resumo: Emuurmtorm de depoimento, este artigo situa o romance histónico Umamor anarquista, que o autor publicou em2005, no conjunto de sula produção literária. Tambémanalisa as opções de estrutura e de linguagenm usadas neste romance que quer apresentar a experiêndia da implantação do anarquismo no Brasil coma criação da Colônia Cecília, no Paraná. Fecha o artigo uma reflexão que modifica a perspectiva sobre estegênero: todo romance histórico pertence mito mais ao momento enque foi escrito do que ao nmomento emque transcorremos fatos, pois o que se entende por passado é uma construção do agora.

Pallavres-chave: Ficção histórica. Colônia Cecília. Anarquismo
Abstract: As a testimmony, this article situates the historical novel Umamor anarquista, that the author published in 2005 in the whole of his literary production. It also analyzes the options of structure and language used in this novel that wants to present the experience of deploynment of anarchismin Brazil with the creation of Colônia Cecilia, Paraná. Closes the article with a reflection that changes the perspective on this genre: all historical novel belongs more to the time it was witten than the time who spend the facts because what is meant by a construction of the past is now.

Key-nords: Historical fiction. Colônia Cecília. Anarchism 

Não sendo anarquista, embora partilhe de muitas de suas posturas libertárias, eu não tinha um motivo ideológico para escrever um romance sobre a Colônia Cecília, instalada no Brasil, em 1890, por um grupo de italianos. Também não sou propriamente um romancista histórico, desses que se alimentam de passagens emblemáticas de outros tempos para construir relatos cativantes, transportando o leitor ao passado, em uma experiência de alteridade temporal.

Poderia dizer que nada, ou muito pouco, me ligava a essa passagem da história do sul do Brasil antes do ano de 1994. Eu a conhecia pelos livros que ela tinha gerado - um romance ingênuo e literariamente fraco de A fonso Schmidt (Colônia Cecília, 1942), uma reportagem fluente, mas insatisfatória, de Newton Stadler de Sousa (O anarquismo da Colônia Cecília, 1970), o relato memorialístico de Anarquistas, graças a Deus (1979), de Zélia Gattai, e referências avulsas em livros, revistas e jornais. Era um episódio opaco para mim.

Naquele início dos anos 1990, eu estava trabal hando num pequeno conjunto de contosquetratavadochoqueentre o meio rural e a cidade grande, matéria bastante biográfica, pois eu tinha acompanhado, na década de 1970, o fim de um modelo de agricultura manual e o início da mecanização do campo, que fez com que toda uma região do Paraná, meu estado natal, sofresse um profundo desequilíbrio, gerado pelo êxodo rural, criando uma população desenraizada, saudosa do campo, um campo desaparecido com a entrada principalmente da cultura da soja, responsável pela transformação de vastas regiões antes populosas em desertos humanos. Era esta a minha preocupação naquele momento: criar algumas trajetórias ficcionais que revelassem este conflito do não-pertencimento. Estes textos só ganharam forma de livro em 2002, quando minha primeira coletânea de contos, Hóspede secreto, recebeu o Prêmio Cruz e Sousa e foi publicada pela Fundação Catarinense de Cultura.

Antes de publicar este livro que tanto tempo me custou, estreei na ficção com um romance, Chove sobre 
minha infância (Record, 2000), obra anfíbia, que passa do registro memorialístico (uma grande tradição na cultura brasileira) para a ficcionalização totalmente livre. Como eu me valho de recursos estilísticos e narrativos da autobiografia para fazer ficção, nomes de pessoas e fatos de minha infância são postos dentro de um maquinismo ficcional, que passa a funcionar com independência. Nesse romance, eu ainda me fixava no fim de um ciclo agrícola, que agora era substituído, na trajetória do narradorpersonagem, pelo mundo da cultura. 0 eixo narrativo é bastante tran sparente: como herdar a cultura cosmopolita vindo de uma família de agricultores analfabetos, sem negar esta origem nem repetir a sua carência de discurso.

Marcado por tal obsessão, eu ampliava, em outros gêneros, meu campo de interesse. No mesmo ano, apareceria meu livro de poemas Venho de um país obscuro, mescla de textos mais culturais e de outros mais autobiográficos, numa expressão de poesia pelas formas da prosa, assim como em Chove sobre minha infância eu tinha feito o inverso, valera-me das formas de poesia para compor um texto em prosa. A mesma busca, tanto estilística quanto temática, foi ainda tentada no vol ume de crônicas Herdando uma biblioteca, o mais autobiográfico dos quatro títulos, embora o vírus da ficção também se manifeste nele. Eu queria mostrar como se forma um leitor num universo absolutamente vazio de livros. Este projeto ocupou-me durante mais de uma década e achei que estava bem resolvido, em quatro gêneros literários distintos, em obras que tratam de maneira diferente a minha circunstância.

Delimitado este território, desejava fugir dele, para conquistar outros. Não queria ficar rotulado como um escritor autobiográfico no sentido raso do termo, risco que eu estava correndo por dar tratamento tão reiterativo a al guns caminhos literários.

Se gastei mais de uma década com esta produção, desde 1994 eu vinha escrevendo uma nova história. Entendo o verbo escrever de uma maneira mais flexível. 
Não se refere apenas ao momento em que paramos a vida para preparar um texto. Eu escrevo muito mais antes da escrita, durante as elaborações interiores da história, momento em que convivo com ela, pesquiso, leio, faço projetos, visito lugares, converso com pessoas, tomo notas e adquiro familiaridade com situações seminais.

Tudo se iniciou de forma espontânea. Em 1994, eu trabalhava em uma pequena editora universitária, à qual foi submetido o trabal ho de um médico sobre seus antepassados anarquistas. Li todo o material, encontrando uma competente pesquisa sobre a vinda para o Paraná de Giovanni Rossi e demais anarquistas. 0 autor, Cândido de Mello Neto, tinha passado pelos principais arquivos do mundo para garimpar um material muito importante, emboral hefaltasse a mínima noção esti lística e estrutural. Dediquei-me a este material bruto para dar-Ihe um formato de livro e, meses depois, saí vencido. Por mais que mudasse, tudo não passava de um arquivo, produzido com intenções de guardar uma memória familiar, e nunca chegaria a ser um trabalho literário. E ele foi publicado assim: O anarquismo experimental de Giovanni Rossi (Editora UEPG, 1997). Durante minha intervenção como editor desta pesquisa, conversei muito com al guns descendentes e visitei o lugar da Colônia Cecília, uma região hoje circundada por campos de soja.

Do primeiro cemitério anarquista - eles não podiam enterrar seus mortos no campo santo por serem ateus - não há sinais, é apenas uma terra sobre a qual os descendentes hoje plantam. Para mim, este seria o eixo do romance - a procura, nos dias atuais, do local exato em que os primeiros anarquistas foram enterrados. 0 outro fato central seria o amor livre: experiência científica (Rossi e a Colônia pagaram tributo ao cientificismo do século XIX) de partilhar a mulher com o maior número de homens, para que os filhos não fossem de um pai, e sim produto coletivo. A proposta do amor livre era uma metáfora de todo o projeto anarquista. Partilhar a mulher como quem divide o pão e a terra. 
Havia, no entanto, um fato imprevisível para a mente cartesiana de Rossi. Ele acabou se apaixonando pela mulher que serviu como experiência amorosa. No final, quando a Colônia se desfez, o ex-socialista estabeleceu uma relação burguesa com ela, voltando à Itália, depois de passagens, agora como um conceituado professor de disciplinas agrícolas, por dois estados vizinhos: Rio Grande do Sul e Santa Catarina. Rossi, o idealista, e a Colônia Cecília, um verdadeiro laboratório social, traziam a inviabilidade de uma sociedade construída ideologicamente, pois haveria sempre forças individuais se impondo, forças que poderiam ser justas (como o amor) ou injustas (como o egoísmo). Rossi sai da experiência desiludido com o socialismo, uma desilusão que se tornou tão frequente ao longo do século XX.

Eu queria contar esta história sem tomar partido, apenas destacando as contradições vividas por uma nova ordem social. Tinha o enredo, sabia como começar, conduzir e finalizar a história. Mas me faltava o essencial. Em que linguagem e em que ritmo narrar? Fiz al gumas abordagens sem encontrar o tom do texto.

Um outro problema surgiu. Como narrar a vida desses italianos sem conhecer a Itália, sem estudar as regiões de onde vieram os integrantes do grupo? Acreditava que o romance devia se passar também em terras italianas, para compor um grande painel com esse contingente de questionadores que chegou ao Brasil atraído pela pregação anarquista, difundida em jornais especializados, e também pela fartura do Novo M undo. Sem conhecer bem o país de origem, eu não poderia registrar os dramas dos personagens reais, que chegavam à Cecília e partiam logo em seguida, depois de comprovar que nem socialismo pleno nem fartura havia ali.

Em 1999, resolvi, como exercício de estilo, traduzir todos os textos de Rossi sobre o Paraná. Com a ajuda de uma amiga, M arzia Terenzi Vicentini, vertemos para o português quatro ensaios de Rossi sobre a vinda dos italianos, os primeiros meses da Colônia, o amor livre 
e uma projeção futurística do Paraná ( $A$ colônia Cecília $e$ outras utopias, 2000). Durante a tradução, constatei que estava dando uma fluência para o texto de Rossi que não existia no original. Por meio da tradução, eu nada mais fazia do que procurar o tom do romance que pretendia escrever. Eu me apropriei deste ritmo e o desenvolvi no romance quando, alguns anos depois de publicada a tradução, passei a produzir a narrativa.

Por motivos profissionais, só pude dar prioridade ao livro em finais de 2003. Não faço parte do grupo de romancistas que consegue alinhavar apenas algumas centenas de palavras por mês. Só consigo escrever quando me entrego totalmente ao livro, quando sei que terei tempo suficiente para fazer a primeira versão da história, o copião. Assim, entre novembro de 2003 e fevereiro de 2004, trabalhei no romance, nunca menos de 8 horas diárias, mesmo quando estava na praia, com a família. 0 livro começava com um personagem no presente, indo em busca do cemitério dos renegados, e depois pulava para o período histórico da Colônia.

Como em outras vezes, tenho sempre que eliminar o primeiro capítulo quando termino de escrever. Ele serve apenas como um estímulo, mas o ritmo só me chega depois. Findo o copião, passo um ano nos trabalhos de revisão, porque escrevo muito rápido, num estado de compulsão, para obter uma velocidade de escrita que seja sintonizada pelo leitor. Logo, a revisão é o momento mais difícil, quando consigo um distanciamento crítico para cortar trechos e acertar o tom, lendo todo o livro em voz alta para que aflorem as frases artificiais e eu possa dar ao conjunto o fluxo de minha respiração, que é a mais natural e original forma estilística que um autor pode conquistar. Nestes trabal hos de ajuste, sempre elimino o primeiro capítulo, pois sinto que ele guarda uma função meramente introdutória e me repugna tudo que não seja essencial em uma obra.

Durante os momentos que antecederam a escrita do romance, tive outra dúvida. Não sou, como já disse, um 
romancista histórico e não estava em meus planos fazer um livro numa linguagem do século XIX, com colonos falando como pessoas eruditas ou como simplórios. Não queria uma linguagem de época no romance, porque 0 objetivo não era fazer um relato histórico tradicional, com uma verossimilhança artificiosa. Eu imaginava um romance contemporâneo sobre fatos ocorridos um século antes. A tradução dos textos de Rossi mostrara ser possível escrever a história em uma linguagem próxima de mim e dos leitores. Eu queria, estilisticamente, trazer os personagens para os dias atuais, num movimento inverso àquele praticado pelas obras históricas.

Comecei este ensaio dizendo que não havia vínculos entre a Colônia Cecília e minha história pessoal e literária. Havia um único vínculo, que se tornou de grande importância paraaautenticidadehumanadospersonagens. A Colônia Cecília era também uma experiência agrícola, e eu conhecia o mundo rural de forma bastante viva. 0 cotidiano daqueles imigrantes não se distanciava muito do que vivi na infância, quando frequentava pequenas propriedades que usavam os mesmos métodos artesanais de trabalho, muitas delas tocadas por descendentes de italianos. Embora a Colônia Cecília tenha surgido no sul do Paraná (mais precisamente em Palmeira) e eu tenha passado a infância no Norte e depois no Centro do mesmo estado, região desbravada a partir de 1910, conheci as lavouras antes da mecanização. A vida da comunidade anarquista tinha para mim uma face familiar.

A percepção desta proximidade e meu projeto de uma escrita que não fosse pitoresca levaram-me à estrutura do livro, narrado em terceira pessoa, com passagens em primeira e inúmeros momentos de discurso indireto livre, para permitir o contraponto da visão dos personagens, que assim podem se manifestar, dentro de uma lógica anarquista (isto é, não-centralizadora) do enredo. Se fosse apenas um ponto de vista do começo ao fim, correria o risco de criar um discurso monolítico sobre a Colônia. Se eu usasse uma multiplicidade deles, 
construiria uma narrativa fragmentária demais, em que tal vez as partes não constituíssem um todo, porque tanto o conto como o romance, para mim, devem ter a forma de uma esfera. M esclando vozes e cartas, mas subordinandoas, estruturalmente, a um narrador em terceira pessoa, eu conseguia dar mais expressividade ao relato, sem torná-lo uma al garavia.

Outra solução estrutural importante foi o recurso das cartas. Embora seja algo muito usado, não trazendo maiores novidades, ele se encaixava perfeitamente no conjunto que estava sendo construído.

Como não pretendia fazer História nem defender ideologias, e sim levantar um romance que pudesse dar prazer estético e também desvelar alguns fatos sobre este episódio tão fascinante, havia a necessidade de relatar acontecimentos históricos e ideológicos sem prejudicar a narrativa, sem transformar a fala dos personagens ou 0 relato do narrador em defesa de um programa político ou em resumo do enredo. Contumaz missivista, Rossi usava as cartas para se comunicar com amigos e parentes e também para fazer propaganda, um pouco exagerada, dos sucessos da Colônia. Este gênero textual era um perfeito instrumento de apoio à narrativa.

Nas cartas, a maioria delas escritas com dados reais, mas reorganizados, vai sendo narrada a trajetória da Cecília, segundo a ótica propagandística de Rossi. Elas trazem a linguagem da ideologia, são os textos que falam dos avanços da Colônia. Mas grande parte do livro é composta por capítulos em que se conta o dia a dia da comunidade, em que todas as contradições afloram, despolitizando as informações divulgadas por Rossi. Neste momento, manifesta-se a linguagem da vida, e os personagens ganham espessura humana, deixando de ser apenas cobaias de um experimento para se tornarem seres com sonhos, frustrações, medos, crenças e sentimentos baixos. Não há aqui o idealismo puro, mas os limites que a realidade e os viventes impõem a qualquer idealismo. A alternância de um capítulo e uma carta cria uma relação desmitificadora, 
pois entram em atrito a linguagem da ideologia e a linguagem da vida. Forma-se um vácuo entre el as, e o leitor vai percebendo até que ponto o sonho é praticável e de que forma ele se deteriora nas relações humanas.

No final do romance, Rossi percebe que somente a linguagem da vida pode dar conta da verdade, a outra contém o credo, mas este credo, criação do homem político, não se sustenta numa comunidade se não for imposto, o que contraria o centro da proposta anarquista: o fim de todas as formas de autoridade. A realidade é maior e mais complexa do que as teorias que pretendem moldá-la.

Há um processo narrativo constituído a partir dessa progressiva deterioração do sonho coletivista. No início, o romance trabalha com uma grande variedade de personagens, que entram e saem de cena. A Cecília começou modestamente, chegou a contar com 250 componentes, mas a maioria teve uma presença muito transitória. Assim, neste momento, o personagem principal é a própria Colônia, entidade coletiva, que se sobrepõe a seus integrantes. Os personagens são quase figurantes, porque o comunitário está sendo afirmado.

Significativamente, depois das desilusões, o romance centra-se mais no drama vivido pelos partícipes dos dois episódios de amor livre, havendo um aprofundamento destes personagens. 0 coletivo dá lugar ao individual e o romance entra na sua fase mais intensa, quando os dramas íntimos, que sempre estiveram em atrito com os dogmas, são priorizados, definindo melhor os personagens, que ganham uma importância crescente, até o final do livro, quando tudo não passa de lembrança difusa na memória de um sobrevivente.

Dos leitores que se manifestaram sobre este livro, apenas o ficcionista Sérgio Sant'Anna percebeu esta intenção estrutural de modificar o modo de narrar para cifrar nele o enredo, preparando o epílogo - única cena que se passa na Itália, mais precisamente em Pisa, escrita sem que eu conhecesse a cidade. 
E aí retomo um fio deixado solto no início deste ensaio. Em determinado momento, percebi que devia escrever prioritariamente sobre o período da Colônia (1890-1894) e, portanto, sobre o Paraná, criando personagens que expressassem, numa linguagem viva, um conhecimento que eu tinha da rotina agrícola e dos conflitos com o ideário socialista e anarquista que eu intuíra na leitura dos documentos coletados por Cândido de $\mathrm{M}$ ello $\mathrm{N}$ eto e em outras fontes. Não fazia sentido, numa obra de ficção, propor um estudo histórico da Colônia: eu devia dar vida a estes personagens.

Movido por tal convicção, criei a personalidade de cada um deles, mantendo seus nomes reais e os principais acontecimentos históricos, mas sem deixar que a História sufocasse o sopro humano queeu, como pequeno demiurgo, insuflava nessas figuras retiradas de documentos.

Coloquei nestes personagens históricos o mundo que eu trazia dentro de mim, dei-Ihes minha linguagem, meu sangue, transferi para suas falas palavras que amadureceram no meu trabalho literário, enfim, criei um deslocamento que fez com que o longe, tanto no tempo como no espaço, ganhasse uma súbita proximidade. É nesse processo de deslocamento que se ergueu o texto literário, livre da fidelidade à História, da qual ele dá conta de forma indireta, mas, nem por isso, menos verdadeira.

Se Chove sobre minha infância não são minhas memórias, mas um romance que deslocava elementos memorialísticos para fins ficcionais, Um amor anarquista desloca fatos históricos para construir uma narrativa contemporânea, que pretende falar de uma matéria atual, a falência das ideologias diante das forças individuais.

Em fevereiro de 2005, quando o romance já estava pronto, encontrei em um sebo o livro Heterodoxia, de Ernesto Sabato (Papirus, 1993), e li sua reflexão sobre os personagens de ficção e a realidade:

Quando Shakespeare apanha heróis da história, transforma em contemporâneosseus. Ú nica forma de não erigir marionetes que só existem no papel. 
Afinal de contas, o humano é eterno: o amor, a morte, o destino. A melhor maneira de fazer falar um personagem histórico como um ser vivente é fazendo-o falar como [...] contemporâneo" (SÁBATO, 1993, p.133).

Encontrava-se plenamente justificada, por um dos mai ores escritores da atual idade, e o que mais claramente refletiu sobre a escrita, a opção de trazer para os dias de hoje e para a minha linguagem a linguagem de um homem que vem de uma formação muito específica, as histórias de Giovanni Rossi e seu séquito de idealistas que se internaram em matas brasileiras para testar na prática social as propostas anarquistas e socialistas, descobrindo que, esteja onde estiver e viva da forma que viver, o homem é sempre comandado por forças incontroláveis.

Quando visito o lugar onde funcionou a Colônia Socialista Cecília, mesmo não havendo mais nenhum resquício material dela, sinto que tudo está acontecendo num agora do qual eu hoje também faço parte. $\mathrm{Não}$ há sensação mais reconfortante do que esta. 


\section{Referências}

DE SOUSA, Newton Stadler. O anarquismo da Colônia Cecília. Rio de Janeiro: Civilização Brasileira, 1970.

GATTAI, Zélia. Anarquistas, graças a Deus. Rio de Janeiro: Record, 1979.

ROSSI, Giovanni. Colônia Ceciliza e outras utopias. Tradução de M arzia Terenzi Vicentini e M iguel Sanches Neto. Curitiba: Imprensa Oficial do Estado, 2000.

SABATO, Ernesto. Heterodoxia. Tradução de Janer Cristaldo. Campinas: Papirus, 1993.

SA NCHES NETO, M iguel. Chove sobre minha infância. Rio de Janeiro: Record, 2000.

_____- Hóspede secreto. Rio de Janeiro: Record, 2003.

2004.

-Venho de um país obscuro e outros poemas. Rio de Janeiro: Bertrand Brasil, 2005.

. Um amor anarquista. Rio de Janeiro: Record, 2005.

. A primeira mulher. Rio de Janeiro: Record, 2008.

. Chá das cinco com o vampiro. Rio de Janeiro: Record, 2010.

SCH M IDT, Afonso. Colônia Cecília. São Paulo: A nchieta, 1942.

[Recebido em 30 de julho de 2012

e aceito para publicação em 30 de julho de 2012] 